\title{
Ensuring Adequate Calcium intake on a Plant-Based Diet
}

\author{
Stewart Rose* and Amanda Strombom \\ Plant-Based Diets in Medicine, USA
}

Submission: October 04, 2019; Published: October 16, 2019

*Corresponding author: Stewart Rose, Vice President, Plant-Based Diets in Medicine, 12819 SE 38th St, \#427, Bellevue, WA 98006, USA

\begin{abstract}
Patients on a plant-based diet consume no dairy products and so must get their calcium from plant foods. Fortunately, a number of plant foods can supply the calcium needed. However, care needs to be taken to obtain calcium from foods that have a low oxalate content and therefore are more bioavailable. Concern about reduced bioavailability due to phytate is less of an issue for those on a plant-based diet because they develop bacterial flora that effectively degrades it. Epidemiologic studies show that people on a plant-based diet achieve a bone mineral density equal to their omnivore counterparts if their calcium intake is adequate. However, plant-based diets vary in their content. While some patients on a plant-based diet achieve adequate calcium intake, many don't. In order to ensure adequate calcium intake, patients need to be counseled to emphasize foods with a high calcium content. Patients should also be counseled on dietary factors that decrease calcium retention, particularly sodium. Almost half the American public take calcium supplements. This can be helpful for patients on a plant-based diet. Obtaining calcium from plant foods has the advantage of avoiding the saturated fat and cholesterol in dairy products, and providing other nutrients, including fiber and phytonutrients, absent in dairy.
\end{abstract}

Keywords: Absorption; Bioavailability; Bone mineral density; Calcium; dairy; oxalic acid; phytate; plant-based diet; vegan; vegetarian

Abbreviations: BMD: Bone Mineral Density; Ca: Calcium 1,25(OH)2 D- 1,25 dihydroxyvitamin D PTH: Parathyroid Hormone; RDA: Recommended Daily Allowance; TRPV5: Transient Receptor Potential Cation Channel Vanilloid Family Member 5; VDR: Vitamin D Receptor

\section{Introduction}

Calcium (Ca) is the most abundant mineral in the body. The only source of calcium is from the diet. It is found in some foods, added to others, available as a dietary supplement, and present in some medicines (such as antacids). Calcium is required for vascular contraction and vasodilation, muscle function, nerve transmission, intracellular signaling and hormonal secretion, although less than $1 \%$ of total body calcium is needed to support these critical metabolic functions. The remaining 99\% of the body's calcium supply is stored in the bones and teeth where it supports their structure and function [1]. Serum calcium is very tightly regulated and does not fluctuate with changes in dietary intakes. The body uses bone tissue as a reservoir for, and source of calcium, to maintain constant concentrations of calcium in blood, muscle, and intercellular fluids [1]. Calcium insufficiency manifests as decreased bone mass and osteoporotic fracture. In the rapidly growing child, calcium deficiency causes rickets. Low levels of intestinal calcium resulting from low dietary intakes have also been associated with increased risk of kidney stones and colon cancer [2]. This is probably due to the decreased binding and increased absorption of oxalic acid, the main constituent of kidney stones, and of carcinogens such as bile acids [3]. Calcium's metabolism is regulated by 3 major transport systems: intestinal absorption, renal reabsorption, and bone metabolism. Calcium transport in these tissues is regulated by a homeostatic hormonal system that involves parathyroid hormone, 1,25 dihydroxyvitamin $\mathrm{D}$, ionized calcium, and the calcium sensing receptor [1,3].

\section{Intestinal Absorption}

The transfer of calcium across the intestinal barrier occurs through both saturable (transcellular) and non-saturable (paracellular diffusion) pathways [4-8]. The saturable component of $\mathrm{Ca}$ absorption is prevalent in the proximal small intestine (i.e. duodenum and jejunum) and is under nutritional and physiological regulation. This is an energy dependent pathway whereby Ca movement from the mucosal-to-serosal side of the intestinal barrier can occur against a concentration gradient $[8,9]$. In contrast, passive transport occurs throughout the length of the intestine and is a non-saturable, linear function of luminal Ca concentration (e.g. 13\% of luminal load per hour in humans $[7,8]$. The non-saturable portion of $\mathrm{Ca}$ absorption in the human ileum is vitamin D sensitive $[7,8]$, as is the saturable pathway to a lesser degree.

In the case of low intake of calcium, the saturable transport pathway is up regulated, a process mediated by increased renal production of 1,25 dihydroxyvitamin D $(1,25(\mathrm{OH}) 2 \mathrm{D})$ [10]. 
Dawson-Hughes et al. found that in women, the efficiency of Ca absorption increased by $32 \%$ within one week of reducing dietary Ca intake from $2000 \mathrm{mg} / \mathrm{d}$ to $300 \mathrm{mg} / \mathrm{d}$ [11]. Consistent with this, low vitamin D status, as well as deletion/mutation of the vitamin D receptor (VDR) or 25 hydroxyvitamin D- $1 \alpha$ hydroxylase (CYP27B1) genes, limit Ca absorption by reducing the saturable pathway.

\section{Bone Metabolism}

Calcium metabolism is regulated in large part by the parathyroid hormone (PTH)-vitamin D endocrine system, which is characterized by a series of homeostatic feedback loops. The rapid release of mineral from the bone is essential to maintain adequate levels of ionized calcium in serum. During vitamin D deficiency states, bone metabolism is significantly affected as a result of reduced active calcium absorption. This leads to increased PTH secretion as the calcium sensing receptor in the parathyroid gland senses changes in circulating ionic calcium. Increased PTH levels induce enzyme activity ( $1 \alpha$-hydroxylase) in the kidney, which converts vitamin D to its active hormonal form, calcitriol. In turn, calcitriol stimulates enhanced calcium absorption from the gut. Not surprisingly, the interplay between the dynamics of calcium and vitamin D often complicates the interpretation of data relative to calcium requirements, deficiency states, and excess intake [1].

In addition to the well-established effects that estrogen has on bone and bone cells [12-14], estrogen can influence Ca metabolism in several ways [15]. In a comparison of pre and post-menopausal women, Heaney et al. found that calcium balance fell significantly in post-menopausal women and that this was due to both a reduction in calcium absorption and an increase in urinary calcium loss [12]. Estrogen loss can reduce the serum level of $1,25(\mathrm{OH}) 2 \mathrm{D}$, but this can be reversed by estrogen repletion and is accompanied by an increase in fractional calcium absorption [16].

\section{Renal Reabsorption}

Calcium leaves the body mainly in urine and feces, but also in other body tissues and fluids, such as sweat. Calcium excretion in the urine is a function of the balance between the calcium load filtered by the kidneys and the efficiency of reabsorption from the renal tubules [17]. Nearly 98 percent of filtered calcium (i.e., glomerular filtrate) is reabsorbed by either passive or active processes occurring at four sites in the kidney, each contributing to maintaining neutral calcium balance. Seventy percent of the filtered calcium is reabsorbed passively in the proximal tubule.

Active calcium transport is regulated by the calcium sensing receptor located in the ascending loop of Henle, where, in response to high calcium levels in the extracellular fluid, active reabsorption in the loop is blocked through actions of the calcium sensing receptor. In contrast, when the filtered calcium load is low, the calcium sensing receptor is activated, and a greater fraction of the filtered calcium is reabsorbed. In the distal tubule, the ion channels known as transient receptor potential cation channel vanilloid family member 5 (TRPV5) control active calcium transport and this process is regulated by calcitriol and estradiol. Finally, the collecting duct also can participate in passive calcium transport, although the relative percentage of total calcium reabsorption in the collecting duct is low. Overall, a typical daily calcium loss for a healthy adult man or woman via renal excretion is $5 \mathrm{mmol} /$ day [18]. Disruption of any of these mechanisms leads to abnormal calcium homeostasis. In chronic kidney disease, disturbances in calcium homeostasis are common and, as GFR decreases, disturbances in calcium homeostasis increase [19]. Healthy vegans who have a lower than desirable Ca intake can still maintain sufficient Ca status through the activation of the saturable pathway and through increased renal absorption.

\section{Epidemiology}

\section{Bone Density}

Several studies have shown that vegans have the same bone density (BMD) and fracture rates as omnivores [20-23]. However, some studies did not [24]. The differences may be a result of different diets within the spectrum of plant based diets. Some vegan diets have higher intakes of calcium than others. This may be particularly true of east Asian plant-based diets. In one study of those who follow a plant-based diet, subjects who had at least $525 \mathrm{mg}$ calcium per day had the same fracture risk as omnivores, but those whose intake was less than $525 \mathrm{mg}$ per day had a higher risk of fracture [25]. So it appears that at a Ca intake level of $525 \mathrm{mg}$ and above, the fracture rates of vegans are equivalent to the fracture rate of omnivores. With aging and after menopause, fractional calcium absorption has been reported to decline on average by 0.21 percent per year after 40 years of age [1].

\section{Nutrition}

Many plant foods are a good source of calcium and the absorption of calcium from them is often better than from dairy products. However, oxalic acid, found naturally in some plants, binds to calcium and can inhibit its absorption [1]. The high bioavailability of calcium from low oxalate vegetables, relative to milk, suggests two things. First, the fibers in the vegetables do not inhibit calcium absorption. This has been confirmed with purified fibers $[26,27]$. Second, low oxalate vegetables may contain calcium absorption enhancers that have not yet been identified [26]. In general, calcium absorption is inversely proportional to the oxalic acid content of the food. Thus, calcium bioavailability is low from both American and Chinese varieties of spinach (5\%) and rhubarb, intermediate from sweet potatoes (25\%), and high from low oxalate vegetables such as kale (50\%), broccoli (62\%), and bok choy (54\%). A notable exception to this generalization is soybeans. Soybeans are rich in both oxalate and phytate, yet soy products have relatively high calcium bioavailability [26]. 
High intake of fruits and vegetables have been associated with a benefit to bone health [28-30]. Potassium levels in fruits and vegetables have been a leading candidate for this benefit. However, in a large Scottish study, flavonoid intake was more strongly related to bone health than fruit and vegetable intake in general [31]. Flavonoids are polyphenolic compounds, some of which have specific effects on osteoblasts or osteoclasts that reduce age-related bone loss [32]. Observational studies have limited ability to distinguish the effect of potassium on bone in the context of many other constituents that may influence bone such as flavonoids. It must also be remembered that some fruits and vegetables have specific positive effects on bone metabolism, which are independent of the alkalizing action of vegetarian diets. For example, the consumption of onions, [33] and of tomatoes, berries, salad greens and green vegetables may be significantly correlated with lower bone resorption and higher BMD of the lumbar spine in humans [34]. Blue fruits, such as plums and blueberries were also shown to inhibit bone resorption and to increase BMD in humans $[35,36]$.

\section{Antinutrients}

Urinary calcium losses account for $50 \%$ of the variability in calcium retention [37]. Of the nutritional factors thought to influence urinary calcium losses (protein, caffeine and sodium intake), sodium appears to be the most important factor. Because sodium and calcium share some of the same transport systems in the proximal tubule, each $2300 \mathrm{mg}$ sodium excreted by the kidney pulls $40-60 \mathrm{mg}$ calcium out with it [38]. High protein intake also increases calcium excretion and was therefore thought to negatively affect calcium status [26,39]. However, more recent research suggests that high protein intake also increases intestinal calcium absorption, effectively offsetting its effect on calcium excretion, so whole body calcium retention remains substantially unchanged [40].

Table 1: Recommended Dietary Allowances for Calcium [1].

\begin{tabular}{|c|c|c|c|c|}
\hline Age & Male & Female & Pregnant & Lactating \\
\hline $0-6$ months & $200 \mathrm{mg}$ & $200 \mathrm{mg}$ & & \\
\hline $7-12$ months & $260 \mathrm{mg}$ & $260 \mathrm{mg}$ & & \\
\hline $1-3$ years & $700 \mathrm{mg}$ & $700 \mathrm{mg}$ & & \\
\hline $4-8$ years & $1,000 \mathrm{mg}$ & $1,000 \mathrm{mg}$ & & $1,300 \mathrm{mg}$ \\
\hline $9-13$ years & $1,300 \mathrm{mg}$ & $1,300 \mathrm{mg}$ & & $1,000 \mathrm{mg}$ \\
\hline $14-18$ years & $1,300 \mathrm{mg}$ & $1,300 \mathrm{mg}$ & $1,000 \mathrm{mg}$ & \\
\hline $19-50$ years & $1,000 \mathrm{mg}$ & $1,000 \mathrm{mg}$ & & \\
\hline $51-70$ years & $1,000 \mathrm{mg}$ & $1,000 \mathrm{mg}$ & & \\
\hline $71+$ years & $1,200 \mathrm{mg}$ & $1,200 \mathrm{mg}$ & & \\
\hline
\end{tabular}

Table 2: Calcium content of various foods.

\begin{tabular}{|c|c|c|}
\hline Food & Calcium (mg/100 cal serving) & Absorption Rate \\
\hline Bok Choy & $870 \mathrm{mg}$ & Medigh \\
\hline Collard Greens & $609 \mathrm{mg}$ & High \\
\hline Orange Juice (calc fortified) & $320 \mathrm{mg}$ & Medium \\
\hline Tofu (set with calcium) & $287 \mathrm{mg}$ & \\
\hline
\end{tabular}




\section{Orthopedics and Rheumatology Open Access Journal (OROAJ)}

\begin{tabular}{|c|c|c|}
\hline Kale & $270 \mathrm{mg}$ & High \\
\hline Broccoli & $215 \mathrm{mg}$ & Medium \\
\hline Cow's milk (for comparison) & $188 \mathrm{mg}$ & Medium \\
\hline Sesame seeds & $170 \mathrm{mg}$ & High \\
\hline Cabbage & $160 \mathrm{mg}$ & Medium \\
\hline White Beans & $72 \mathrm{mg}$ & Medium \\
\hline Tempeh & $55 \mathrm{mg}$ & \\
\hline
\end{tabular}

These RDAs are not universally recommended and vary from country to country. For instance, in the United Kingdom the RDAs are around half the U.S. levels. Given the data on fracture rates [25] the United Kingdom RDAs appear to be adequate. To meet the recommendations generous portions of plant foods should be eaten (Table 2). Even so, some people will still need help in reaching recommended intakes of calcium. In these cases, supplements will prove very helpful.

\section{Calcium Supplements}

About $43 \%$ of the U.S. population (including almost $70 \%$ of older women) uses dietary supplements containing calcium, increasing calcium intakes on average by about $330 \mathrm{mg} /$ day among supplement users [1,46]. The two main forms of calcium in supplements are carbonate and citrate. Calcium carbonate is more commonly available and is both inexpensive and convenient. Due to its dependence on stomach acid for absorption, calcium carbonate is absorbed most efficiently when taken with food, whereas calcium citrate is absorbed equally well when taken with or without food [47]. Calcium citrate is also useful for people with achlorhydria, inflammatory bowel disease, or absorption disorders [1]. Calcium citrate or malate is a well-absorbed form of calcium found in some fortified juices [48]. Other calcium forms in supplements or fortified foods include gluconate, lactate, and phosphate.

The percentage of calcium absorbed depends on the total amount of elemental calcium consumed at one time; as the amount increases, the percentage absorption decreases. Absorption is highest in doses less than $500 \mathrm{mg}$ [1]. So, for example, one who takes $1,000 \mathrm{mg} /$ day of calcium from supplements might split the dose and take $500 \mathrm{mg}$ at two separate times during the day. Some individuals who take calcium supplements might experience gastrointestinal side effects including gas, bloating, constipation, or a combination of these symptoms. Calcium carbonate appears to cause more of these side effects than calcium citrate [1], so consideration of the form of calcium supplement is warranted if these side effects are reported. Other strategies to alleviate symptoms include spreading out the calcium dose throughout the day and/or taking the supplement with meals.

\section{Medication Interactions}

Calcium supplements have the potential to interact with several types of medications. Individuals taking these medications on a regular basis should discuss their calcium intake with their healthcare providers. Calcium can decrease absorption of the following drugs when taken together: bisphosphonates, benzodiazephines, the fluoroquinolone and tetracycline classes of antibiotics, levothyroxine, phenytoin, and tiludronate disodium [49-51]. Thiazide-type diuretics can interact with calcium carbonate and vitamin D supplements, increasing the risks of hypercalcemia and hypercalciuria [50]. Both aluminum- and magnesium-containing antacids increase urinary calcium excretion. Mineral oil and stimulant laxatives decrease calcium absorption. Glucocorticoids, such as prednisone, can cause calcium depletion and eventually osteoporosis when they are used for months [50].

Studies on human subjects have shown that calcium (Ca) can inhibit iron ( $\mathrm{Fe}$ ) absorption, regardless of whether it is given as Ca salts or in food products. This has caused concern as increased Ca intake commonly is recommended for children and women, the same populations that are at risk of Fe deficiency. However, a thorough review of studies on humans in which Ca intake was substantially increased for long periods shows no changes in hematological measures or indicators of iron status [52].

\section{Discussion}

The patient on a plant-based diet needs calcium the same as their omnivore counterparts. Calcium needs can be met with plant foods, so dairy consumption is not necessary. In fact, obtaining calcium from plant food sources is preferable, in that they provide fiber, vitamins, minerals and phytonutrients, without the price tag of saturated fat and risk for the lactose intolerant. Vegetables also have the advantage of providing phytonutrients which have been associated with greater bone mineral density. Patients should be counseled on which foods are high in bioavailable calcium. Apart from this, patient advice is the same as for omnivores. Special note should be made to avoid excessive sodium.

\section{References}

1. Institute of Medicine Food and Nutrition Board (2010) Dietary Reference Intakes for Calcium and Vitamin D. Washington DC, USA.

2. Shils M, Shike M (2006) Modern nutrition in health and disease. $10^{\text {th }}$ (edn), Lippincott Williams \& Wilkins, Philadelphia, USA.

3. Weaver C, Peacock M (2011) Calcium. Advances in Nutrition 2(3): 290-292.

4. Wasserman R, Taylor A (1969) Some aspects of the intestinal absorption of calcium, with special reference to vitamin D. In: Comar C, Bronner F, (eds), Mineral Metabolism, An advanced treatise. Academic Press, New York, USA. 
5. Pansu D, Bellaton C, Bronner F (1981) Effect of Ca intake on saturable and nonsaturable components of duodenal Ca transport. Am J Physiol 240(1): G32-G37.

6. Heaney R, Saville P, Recker R (1975) Calcium absorption as a function of calcium intake. J Lab Clin Med 85(6): 881-890.

7. Sheikh M, Schiller L, Fordtran JS (1990) In vivo intestinal absorption of calcium in humans. Miner Electrolyte Metab 16(2-3): 130-146.

8. Fleet J, Schoch R (2010) Molecular mechanisms for regulation of intestinal calcium absorption by vitamin D and other factors. Crit Rev Clin Lab Sci 47(4): 181-195.

9. Favus M, Angeid-Backman E, Breyer M, Coe F (1983) Effects of trifluoperazine, ouabain, and ethacrynic acid on intestinal calcium transport. Am J Physiol 244(2): G111-G115.

10. Favus M, Walling M, Kimberg D (1974) Effects of dietary calcium restriction and chronic thyroparathyroidectomy on the metabolism of (3H)25-hydroxyvitamin D3 and the active transport of calcium by rat intestine. J Clin Invest 53(4): 1139-1148.

11. Dawson-Hughes B, Harris S, Kramich C, Dallal G, Rasmussen H (1993) Calcium retention and hormone levels in black and white women on high- and low-calcium diets. J Bone Min Res 8(7): 779-787.

12. Heaney R, Recker R, Saville P (1978) Menopausal changes in bone remodeling. J Lab Clin Med 92(6): 964-970.

13. Hofbauer L, Khosla S, Dunstan C, Lacey D, Spelsberg T, et al. (1999) Estrogen stimulates gene expression and protein production of osteoprotegerin in human osteoblastic cells. Endocrinology 140(9): 4367-4370.

14. Sarma U, Edwards M, Motoyoshi K, Flanagan A (1998) Inhibition of bone resorption by $17 \beta$-estradiol in human bone marrow cultures. J Cell Physiol 175(1): 99-108.

15. Riggs B, Khosla S, Melton L (2002) Sex steroids and the construction and conservation of the adult skeleton. Endocr Rev 23(3): 279-302.

16. Gallagher J, Riggs B, DeLuca H (1980) Effect of estrogen on calcium absorption and serum vitamin D metabolites in postmenopausal osteoporosis. J Clin Endocrinol Metab 51(6): 1359-1364.

17. Peacock M (1988) Renal excretion of calcium. In: Nordin BEC, ed. Calcium in Human Biology. ( $1^{\text {st }}$ edn), Springer-Verlag, London, UK.

18. McCormick C (2002) Passive diffusion does not play a major role in the absorption of dietary calcium in normal adults. J Nutr 132(11): 34283430 .

19. Goodman W (2005) Calcium and phosphorus metabolism in patients who have chronic kidney disease. Med Clin North Am 89(3): 631-647.

20. Ho-Pham L, Nguyen N, Nguyen T (2009) Effect of vegetarian diets on bone mineral density: a Bayesian meta-analysis. Am J Clin Nutr 90(4) 943-950.

21. Knurick J, Johnston C, Wherry S, Aguayo I (2015) Comparison of correlates of bone mineral density in individuals adhering to lacto-ovo, vegan, or omnivore diets: a cross-sectional investigation. Nutrients 7(5): 3416-3426.

22. Ho-Pham L, Vu B, Lai T, Nguyen N, Nguyen T (2012) Vegetarianism, bone loss, fracture and vitamin D: a longitudinal study in Asian vegans and non-vegans. Eur J Clin Nutr 66(1): 75-82.

23. Ho-Pham L, Nguyen P, Le T, Doan T, Tran N, et al. (2009) Veganism, bone mineral density, and body composition: a study in Buddhist nuns. Osteoporos Int 20(12): 2087-2093.

24. Iguacel I, Miguel-Berges M, Gómez-Bruton A, Moreno L, Julián C (2019) Veganism, vegetarianism, bone mineral density, and fracture risk: a systematic review and meta-analysis. Nutr Rev 77(1): 1-18.
25. Appleby P, Roddam A, Allen N, Key T (2007) Comparative fracture risk in vegetarians and nonvegetarians in EPIC-Oxford. Eur J Clin Nutr 61(12): 1400-1406.

26. Weaver C, Proulx W, Heaney R (1999) Choices for achieving adequate dietary calcium with a vegetarian diet. Am J Clin Nutr 70 (3 Suppl): 543S-548S

27. Heaney R, Weaver C (1995) Effect of psyllium on absorption of co-ingested calcium. J Am Geriatr Soc 43(3): 261-263.

28. Tucker K, Hannan M, Chen H, Cupples L, Wilson P, et al. (1999) Potassium, magnesium, and fruit and vegetable intakes are associated with greater bone mineral density in elderly men and women. Am J Clin Nutr 69(4): 727-736

29. Prynne C, Mishra G, O’Connell M, Muniz G, Laskey M, et al. (2006) Fruit and vegetable intakes and bone mineral status: a cross sectional study in 5 age and sex cohorts. Am J Clin Nutr 83(6): 1420-1428.

30. Chen Y, Ho S, Woo J (2006) Greater fruit and vegetable intake is associated with increased bone mass among postmenopausal Chinese women. Br J Nutr 96(4): 745-751.

31. Hardcastle A, Aucott L, Reid D, Macdonald H (2011) Associations between dietary flavonoid intakes and bone health in a Scottish population. J Bone Miner Res 26(5): 941-947.

32. Weaver C, Alekel D, Ward W, Ronis M (2012) Flavonoid intake and bone health. J Nutr Gerontol Geriatr 31(3): 239-253.

33. Matheson E, Mainous A, Carnemolla M (2009) The association between onion consumption and bone density in perimenopausal and postmenopausal non-Hispanic white women 50 years and older. Menopause 16(4): 756-759.

34. Macdonald H, Hardcastle A (2010) Dietary patterns and bone health In: Burckhardt P, Dawson-Hughes B, Weaver C, eds. Nutritional Influences on Bone Health. ( $1^{\text {st }}$ ed), Springer, London, UK.

35. Hooshmand S, Chai S, Saadat R, Payton M, Brummel-Smith K, et al. (2011) Comparative effects of dried plum and dried apple on bone in postmenopausal women. Br J Nutr 106(6): 923-930.

36. Davicco M, Puel C, Lebecque P, Coxam V (2013) Blueberry in Calcium- and Vitamin D-Enriched Fermented Milk Is Able to Modulate Bone Metabolism in Postmenopausal Women. In: Burckhardt P, Dawson-Hughes B, Weaver C, eds. Nutritional Influences on Bone Health. ( $8^{\text {th }}$ edn), Springer, London, UK.

37. NIH Consensus Development Panel on optimal calcium intake (1994) Optimal calcium intake. JAMA 272(24): 1942-1948.

38. Nordin B, Need A, Morris H, Horowitz M (1993) The nature and significance of the relationship between urinary sodium and urinary calcium in women. J Nutr 123(9): 1615-1622.

39. Heaney R (1996) Bone mass, nutrition, and other lifestyle factors. Nutr Rev 54(4 Pt 2): S3-10.

40. Kerstetter J, O’Brien K, Caseria D, Wall D, Insogna K (2005) The impact of dietary protein on calcium absorption and kinetic measures of bone turnover in women. J Clin Endocrinol Metab 90(1): 26-31.

41. Hasling C, Søndergaard K, Charles P, Mosekilde L (1992) Calcium metabolism in postmenopausal osteoporotic women is determined by dietary calcium and coffee intake. J Nutr 122(5): 1119-1126.

42. Barger-Lux M, Heaney R, Stegman M (1990) Effects of moderate caffeine intake on the calcium economy of premenopausal women. Am J Clin Nutr 52(4): 722-725.

43. Calvo M (1993) Dietary phosphorus, calcium metabolism and bone. J Nutr 123(9): 1627-1633. 
44. Heaney R, Rafferty K (2001) Carbonated beverages and urinary calcium excretion. Am J Clin Nutr 74(3): 343-347.

45. Markiewicz L, Honke J, Haros M, Świątecka D, Wróblewska B (2013) Diet shapes the ability of human intestinal microbiota to degrade phytate--in vitro studies. J Appl Microbiol 115(1): 247-259.

46. Bailey R, Dodd K, Goldman J, Gahche J, Dwyer J, et al. (2010) Estimation of total usual calcium and vitamin D intakes in the United States. J Nutr 140(4): 817-822.

47. Straub D (2007) Calcium supplementation in clinical practice: a review of forms, doses, and indications. Nutr Clin Pract 22(3): 288-296.

48. Andon M, Peacock M, Kanerva R, De Castro J (1996) Calcium absorption from apple and orange juice fortified with calcium citrate malate (CCM). J Am Coll Nutr 15(3): 313-316.
49. Shannon M, Wilson B, Stang C (2000) Health Professionals Drug Guide. Stamford, CT: Appleton and Lange.

50. Jellin J, Gregory P, Batz F, Hitchens K (2000) Pharmacist's letter/Prescriber's letter Natural medicines comprehensive database. ( $3^{\text {rd }}$ edn), Therapeutic Research Facility, Stockton, CA, USA.

51. Peters M, Leonard M, Licata A (2001) Role of alendronate and risedronate in preventing and treating osteoporosis. Cleve Clin J Med 68(11): 945-951.

52. Lönnerdal B (2010) Calcium and iron absorption--mechanisms and public health relevance. Int J Vitam Nutr Res 80(4-5): 293-299.

\section{Your next submission with Juniper Publishers will reach you the below assets}

- Quality Editorial service

- Swift Peer Review

- Reprints availability

- E-prints Service

- Manuscript Podcast for convenient understanding

- Global attainment for your research

- Manuscript accessibility in different formats ( Pdf, E-pub, Full Text, Audio)

- Unceasing customer service

Track the below URL for one-step submission https://juniperpublishers.com/online-submission.php 